\title{
Sedentary Behavior Is an Independent Predictor of Mortality in Subjects With COPD
}

\author{
Karina C Furlanetto PhD, Leila Donária MSc, Lorena P Schneider, José R Lopes, \\ Marcos Ribeiro PhD, Karen BP Fernandes PhD, Nidia A Hernandes PhD, and Fabio Pitta PhD
}

\begin{abstract}
BACKGROUND: The terms sedentary behavior and physical inactivity have been confusingly mixed. Although the association between physical inactivity and mortality has been shown previously in subjects with COPD, this association had not yet been investigated with regard to sedentarism. The aim of this work was to investigate the impact of sedentary behavior on mortality of subjects with COPD and to propose a cutoff point of sedentarism with prognostic value. METHODS: In this retrospective cohort study, sedentary behavior was assessed with 2 activity monitors (DynaPort and Sensewear armband) in 101 subjects with COPD from 2006 to 2011. Vital status was then ascertained in 2015. The following 6 variables of sedentary behavior were analyzed: average of metabolic equivalent of task (MET)/d (reflecting intensity); time spent/d lying, sitting, and lying + sitting (reflecting duration of sedentary postures); and time spent/d in activities requiring $<1.5$ MET and <2 MET (reflecting intensity and duration of sedentary time). Cutoff points for sedentarism and their respective prognostic values were investigated for each variable. RESULTS: Forty-one subjects $(41 \%)$ died over a median (interquartile range) follow-up period of 62 (43-88) months. After adjusting for potential confounders in the Cox regression model, cutoff points from variables that combine duration of sedentary time and intensity <1.5 MET or <2 MET were associated with the increased risk of mortality. The strongest independent cutoff for predicting mortality was $\geq 8.5 \mathrm{~h} / \mathrm{d}$ spent in sedentary activities < 1.5 MET (area under the curve 0.76; hazard ratio 4.09, 95\% CI 1.90-8.78; $P<.001)$. CONCLUSIONS: Sedentary behavior was an independent predictor of mortality in subjects with COPD, even adjusting for moderate-to-vigorous physical activity and a number of other variables. Mortality was higher in subjects with COPD who spend $\geq 8.5 \mathrm{~h} / \mathrm{d}$ in activities requiring $<1.5 \mathrm{MET}$. These findings may open room for future studies aiming at decreasing sedentary time as a promising strategy to reduce mortality risk in subjects with COPD. Key words: chronic obstructive pulmonary disease; sedentary lifestyle; physical activity; mortality; longitudinal studies; survival analysis. [Respir Care 2017;62(5):579-587. () 2017 Daedalus Enterprises]
\end{abstract}

Introduction

Reduced level of physical activity in daily life is an important predictor of mortality in patients with COPD. ${ }^{1-4}$

Dr Furlanetto, Ms Donária, Ms Schneider, Mr Lopes, Dr Ribeiro, Dr Hernandes, and Dr Pitta are affiliated with the Laboratory of Research in Respiratory Physiotherapy (LFIP), Department of Physiotherapy, and Dr Ribeiro is also affiliated with the Department of Medicine, Universidade Estadual de Londrina (UEL), Londrina, Brazil. Dr Fernandes is affiliated with the Biological and Health Sciences Research Center, Universidade Norte do Paraná (UNOPAR), Londrina, Paraná, Brazil.
Increased sedentary behavior is also associated with deleterious health effects, which differ from those that can be attributed to reduced physical activity in daily life (or lack of moderate-to-vigorous physical activity). ${ }^{5}$ In fact, the terms sedentary behavior and physical inactivity have been confusingly mixed. However, these are different outcomes, since it is possible for an individual to accumulate large

\footnotetext{
This work was supported by Fundação Araucária and CNPq, Brazil. Dr Furlanetto and Ms Donária are supported by $\mathrm{PhD}$ grants from CAPES/Brazil. Dr Pitta is supported by a research grant from $\mathrm{CNPq} / \mathrm{Brazil}$. The authors have disclosed no conflicts of interest.
} 
amounts of both moderate-to-vigorous physical activity and sedentary behavior throughout the same day. ${ }^{5-8}$

The differentiation between these terms has recently received interest. $5,7,9,10$ The 2 most common definitions of sedentarism are as follows: one based solely on low intensity (activities performed at an intensity $<1.5$ metabolic equivalent of task [MET]) and another that combines low intensity ( $\leq 1.5 \mathrm{MET}$ ) with a large proportion of the day spent in the seated or reclined posture. ${ }^{11}$ Common sedentary behaviors include reading, television viewing, and using a computer, among others. ${ }^{7}$ In contrast, "inactive" should be used to describe those who are performing insufficient amounts of moderate-to-vigorous physical activity, $5,7,9$ (ie, not meeting specified physical activity guidelines, such as engaging in $30 \mathrm{~min} /$ day of activities $\geq 3$ MET on $5 \mathrm{~d} /$ week). ${ }^{12}$

Patients with COPD typically do very little activity at moderate or vigorous intensities, ${ }^{7,13}$ and sedentary behavior is predominant in their daily lives. ${ }^{7,14}$ Previous studies have shown the association between physical activity profile and mortality among many other outcomes in these subjects. ${ }^{1,15-17}$ However, up to this moment, there is no study on COPD that has investigated the association between mortality and variables of sedentary behavior (instead of variables of physical activity), according to the above-mentioned definitions. In addition, there are no available cutoff points of objectively assessed variables of sedentarism that classify patients as sedentary or not as well as there are no studies investigating whether these classifications impact on mortality. Therefore, despite the wellknown links between physical activity in daily life and mortality in COPD and between sedentarism and mortality in the general population, ${ }^{6,18}$ a similar link between sedentarism and mortality has not yet been clearly described in subjects with COPD. Based on this, it was hypothesized that subjects with COPD classified as sedentary would also present a higher risk of mortality than non-sedentary subjects. To investigate this hypothesis, the aims of this study were to propose a cutoff point for sedentarism in subjects with COPD and to investigate its association with mortality.

Dr Furlanetto presented a version of this work at the European Respiratory Society Annual Congress 2016, held September 3-7, 2016, in London, UK.

Correspondence: Fabio Pitta PhD, Departamento de Fisioterapia, CCS, Hospital Universitário de Londrina, Av. Robert Koch, 60, Vila Operaria, 86038-350, Londrina, Paraná, Brazil. E-mail: fabiopitta@uol.com.br.

DOI: $10.4187 /$ respcare.05306

\section{QUICK LOOK}

\section{Current knowledge}

The differentiation between "sedentary behavior" and "physical inactivity" has recently received interest. A sedentary lifestyle has been independently associated with mortality in the general population, regardless of physical activity level. Previous studies in subjects with COPD have shown the association between physical activity variables with mortality among many other outcomes, although the association of sedentary behavior with mortality was not yet investigated.

\section{What this paper contributes to our knowledge}

Sedentary behavior was associated with mortality in subjects with COPD, even adjusting for moderate-tovigorous physical activity and a number of other variables. The study provides an analysis of the cutoff points with prognostic value to identify sedentary subjects with COPD. Avoiding long periods of sedentary behavior reduces mortality risk in subjects with COPD.

\section{Methods}

\section{Sample and Study Design}

This is a cohort retrospective study that used baseline data from a study previously published in this Journal by the present group. ${ }^{19}$ From May 2006 to July 2011, 102 subjects with diagnosis of COPD according to the Global Initiative for Chronic Obstructive Lung Disease (GOLD) ${ }^{20}$ gave written informed consent and were assessed at the Laboratory of Research in Respiratory Physiotherapy, State University of Londrina (Brazil). After baseline assessment, all subjects were enrolled in a prospective interventional study ${ }^{19}$ that investigated the effects of 2 different exercise programs performed during 3 months. However, in that study, no significant changes in physical activity in daily life or sedentary behavior were observed after 3 months of rehabilitation, which indicates that this cohort was not strongly influenced by the effects of pulmonary rehabilitation on physical activity in daily life, as shown previously. ${ }^{21}$ Furthermore, the groups of subjects included in the 2 different exercise programs presented similar time to death when compared with each other and also with the group of dropouts $(P>.05$; data not shown), indicating that the recruitment method did not impact the results.

Inclusion criteria were: diagnosis of COPD according to the GOLD criteria, ${ }^{20}$ clinical stability without infections and exacerbations within the last 3 months before the study, and an absence of severe and/or unstable cardiac disease 


\section{Sedentary Behavior and Mortality in COPD}

and musculoskeletal comorbidity that could interfere with carrying out the proposed assessments. The exclusion criterion was the absence of available baseline data. The analysis of mortality or survival for each subject included in the previous study was performed a posteriori in August 2015 , as described below. The study was approved by the institutional research ethics committee (approval 996.413).

\section{Measurements}

\section{Sedentary Behavior}

Sedentarism variables and time spent in moderate-tovigorous physical activity (ie, $>3$ MET) were assessed at the study entry, when all subjects wore 2 activity monitors simultaneously over 2 weekdays (Tuesday and Wednesday) for $12 \mathrm{~h} / \mathrm{d}$. The 2 -d average was used for the analysis. Reliability of this assessment period (ie, 2 d) was previously shown to be good in subjects with COPD. ${ }^{13,22}$ The 2 activity monitors were the multisensory SenseWear armband (BodyMedia, Pittsburgh, Pennsylvania), which is worn on the upper-posterior region of the right arm, and the triaxial DynaPort activity monitor (McRoberts, The Hague, The Netherlands), which is worn on the patient's waist. Both activity monitors have been validated for COPD. ${ }^{13,23-25}$

Six sedentarism variables were used in this study, and they may be divided into 3 types: (1) 3 variables reflecting time spent/d in sedentary postures (lying time/d, sitting time/d, and the sum of lying and sitting time (lying + sitting time/d) ${ }^{5}$; (2) one variable reflecting intensity of performed activities during the day (average of MET/d) ${ }^{26}$; and (3) 2 variables reflecting the combination of time and intensity (sedentary time spent/d in activities requiring $<1.5$ MET [time/d $<1.5$ MET] and $<2$ MET [time/d $<2$ MET] [since it has been suggested that the range of sedentarism could be extended to activities $<2.0$ MET instead of 1.5 MET] ${ }^{27}$ ).

\section{Mortality}

Vital status was ascertained by telephone contact and officially confirmed by checking the data set of the Center for Information on Mortality, which is responsible for registering all death events in the municipality. These data were collected after formal authorization from the city's Health Secretary. The date of death was recorded (when applicable), and survival time was defined as the time from the baseline assessment to the date of death or the last contact. The last day of follow-up was August 7, 2015. The outcome of this study was all-cause mortality.

\section{Secondary Outcomes}

Lung function was assessed by spirometry according to international recommendations, ${ }^{28}$ and Brazilian reference values from Pereira et $\mathrm{a}^{29}$ were used. Exercise capacity was evaluated by the 6 -min walk test ${ }^{30}$ also considering the reference values from the Brazilian population. ${ }^{31}$ Dyspnea during activities of daily living was assessed with the modified Medical Research Council scale. ${ }^{32,33}$ Anthropometric characteristics, such as height, weight, and subsequent calculation of the body mass index, were objectively assessed, and educational level was reported by all subjects.

\section{Statistical Analysis}

The Shapiro-Wilk test was performed to analyze normality in data distribution. Results are shown as median (interquartile range) or $n(\%)$. Subjects were classified as survivors or non-survivors according to their vital status at the end of the follow-up period, and differences between groups were investigated using an unpaired $t$ test, MannWhitney test, or chi-square test, as appropriate.

Receiver operating characteristic curves were used to determine threshold values with the best sensitivity and specificity to predict mortality. Kaplan-Meier curves with the log-rank tests were performed to analyze the differences of survival over time according to the cutoff value of each sedentarism variable. Cox's proportional-hazard regressions estimated the survival probability of each sedentarism variable (univariate) and were adjusted (multivariate) for sex, age, body mass index, educational level, $\mathrm{FEV}_{1}$ (percent predicted), 6-min walk distance (percent predicted), and time spent in moderate-to-vigorous physical activity, in accordance with univariate regressions and previous studies on COPD. ${ }^{16,34}$ Estimated hazard ratio and 95\% CI were calculated after stratifying for each sedentarism threshold. Skewed variables were log-transformed to normalize their distribution. Statistical analyses were carried out using SPSS 21 (SPSS, Chicago, Illinois) and GraphPad Prism 6.0 (GraphPad Software, La Jolla, California), and the significance level was set at $P<.05$.

\section{Results}

\section{Baseline Characteristics}

One subject was excluded from the study at baseline due to an incomplete daily physical activity assessment; therefore, 101 subjects with COPD were analyzed. Subject characteristics at baseline are shown in Table 1. No subject classified as GOLD I (ie, $\mathrm{FEV}_{1}>80 \%$ predicted) was included, whereas $26 \%$ were GOLD II, $50 \%$ were GOLD III, and $24 \%$ were GOLD IV. 
Table 1. Baseline Characteristics of the Study Population According to Vital Status

\begin{tabular}{|c|c|c|c|c|}
\hline Variable & $\begin{array}{l}\text { All Subjects } \\
(N=101)\end{array}$ & Survivors $(n=60)$ & Non-Survivors $(n=41)$ & $P$ \\
\hline Male sex, $n(\%)$ & $58(57)$ & $27(45)$ & $31(76)$ & .004 \\
\hline Age, median (IQR) y & $66(60-72)$ & $64(59-71)$ & $69(61-74)$ & .033 \\
\hline Weight, median (IQR) kg & $69(55-79)$ & $67(57-78)$ & $71(52-80)$ & .94 \\
\hline Height, median (IQR) m & $1.59(1.53-1.67)$ & $1.58(1.53-1.66)$ & $1.63(1.53-1.68)$ & .38 \\
\hline BMI, median (IQR) $\mathrm{kg} \cdot \mathrm{m}^{-2}$ & $26(21-31)$ & $27(22-31)$ & $25(19-31)$ & .42 \\
\hline $\mathrm{FEV}_{1}$, median (IQR) L & $0.99(0.77-1.35)$ & $1.11(0.81-1.47)$ & $0.88(0.69-1.14)$ & .02 \\
\hline $\mathrm{FEV}_{1}$, median (IQR) \% predicted & $41(30-50)$ & $43(34-58)$ & $34(26-46)$ & .001 \\
\hline $\mathrm{FEV}_{1} / \mathrm{FVC}$, median (IQR) & $51(41-65)$ & $56(43-68)$ & $46(35-57)$ & .009 \\
\hline 6MWD, median (IQR) m & $434(385-495)$ & $455(397-510)$ & $404(334-455)$ & .001 \\
\hline $6 \mathrm{MWD}$, median (IQR) \% predicted & $81(70-88)$ & $85(77-95)$ & $74(61-82)$ & $<.001$ \\
\hline mMRC (0-4), median (IQR) score & $3(2-3)$ & $3(1-3)$ & $3(2-3)$ & .18 \\
\hline Low/high educational level, $n(\%)^{*}$ & $36 / 64(36 / 64)$ & $21 / 39(35 / 65)$ & $15 / 24(38 / 62)$ & .83 \\
\hline No. of comorbidities, median (IQR) & $2(1-3)$ & $1(1-2)$ & $2(0-4)$ & .35 \\
\hline MVPA, median (IQR) h/d & $0.48(0.14-1.24)$ & $0.78(0.29-1.31)$ & $0.25(0.07-0.77)$ & .006 \\
\hline Sitting time, median (IQR) h/d & $5.28(3.95-6.52)$ & $5.00(3.80-6.44)$ & $5.82(4.29-6.44)$ & .15 \\
\hline Lying time, median (IQR) h/d & $1.72(0.56-2.97)$ & $1.29(0.41-2.97)$ & $1.96(0.81-3.05)$ & .21 \\
\hline Lying + sitting time, median (IQR) h/d & $7.52(5.63-8.65)$ & $7.10(5.12-8.35)$ & $8.02(5.98-9.19)$ & .037 \\
\hline $\mathrm{ST} / \mathrm{d}<1.5 \mathrm{MET}$, median (IQR) h/d & $8.21(6.39-10.49)$ & $7.21(5.69-8.35)$ & $8.99(8.04-10.18)$ & $<.001$ \\
\hline $\mathrm{ST} / \mathrm{d}<2 \mathrm{MET}$, median $(\mathrm{IQR}) \mathrm{h} / \mathrm{d}$ & $9.33(7.90-10.49)$ & $8.94(7.41-9.94)$ & $10.28(8.80-11.40)$ & .003 \\
\hline Average of MET, median (IQR) MET/d & $1.45(1.2-1.8)$ & $1.3(1.1-1.6)$ & $1.6(1.3-2.0)$ & .003 \\
\hline $\begin{array}{l}\text { A Mann-Whitney test or independent } t \text { test was used } \\
\text { * Low educational level = illiterate or only primary } \mathrm{s} \\
\mathrm{IQR}=\text { interquartile range } \\
\mathrm{BMI}=\text { body mass index } \\
6 \mathrm{MWD}=6 \text {-min walk distance } \\
\mathrm{mMRC}=\text { modified Medical Research Council scale } \\
\mathrm{MVPA}=\text { time spent/d in moderate-to-vigorous physi } \\
\mathrm{MET}=\text { metabolic equivalent of task } \\
\mathrm{ST} / \mathrm{d}<1.5 \mathrm{MET}=\text { time spent/d in sedentary activitie } \\
\mathrm{ST} / \mathrm{d}<2 \mathrm{MET}=\text { time spent/d in sedentary activities }\end{array}$ & $\begin{array}{l}3 \text { metabolic equivalents of } \\
1.5 \text { metabolic equivalents } \\
\text { metabolic equivalents of ta }\end{array}$ & 2 subjects with missing dat & & \\
\hline
\end{tabular}

Absolute values of moderate-to-vigorous physical activity were significantly correlated with 5 variables reflecting sedentary behavior, as follows: lying time $(\mathrm{r}=-0.48)$, lying + sitting time $(\mathrm{r}=-0.38)$, time $/ \mathrm{d}$ $<1.5$ MET $(\mathrm{r}=-0.74)$, time/d $<2$ MET $(\mathrm{r}=-0.84)$, and average of MET $(\mathrm{r}=0.80)$. There was no correlation between moderate-to-vigorous physical activity and sitting time $(\mathrm{r}=-0.07)$.

\section{Survivors and Non-Survivors}

There was no loss of data from any subject in the follow-up analysis. Forty-one of the subjects (41\%) died over a median (interquartile range) follow-up period of 62 (4388 ) months. Table 1 also compares the characteristics of survivors and non-survivors. Subjects who died were predominantly male and older and presented worse lung function, exercise capacity, and moderate-to-vigorous physical activity level, although with similar educational level, number of comorbidities, and dyspnea sensation during daily life. In addition, subjects who died spent more time in sedentary activities than survivors, as identified by 4 variables: lying + sitting time/d, time/d $<1.5$ MET; time/d $<2$ MET, and the average of MET/d $(P<.05$ for all $)$. The same variables were associated with mortality in the univariate Cox regression model $(P<.05$ for all). The percentage of subjects who reported at least one comorbidity was similar in both groups (80\% from group survivors and $74 \%$ from group non-survivors, $P=.60$ ). There were no between-group differences concerning each related comorbidity, such as arthritis, stable heart diseases, hypertension, diabetes, osteoporosis, or thyroid or vascular diseases $(P>.05$ for all $)$.

\section{Sedentarism Cutoff Points and Mortality}

Table 2 presents the best threshold values of the 6 sedentarism variables to predict mortality in subjects with COPD over the follow-up period. The highest value of area under the curve was found for time/d $<1.5$ MET (0.76). Five of those 6 variables present the range within no or poor discrimination, with low sensitivity and spec- 
Table 2. Sedentarism Cutoff Points for the Prediction of Mortality

\begin{tabular}{|c|c|c|c|c|c|}
\hline Sedentarism Variable & AUC & Sensitivity (\%) & Specificty $(\%)$ & Likelihood Ratio & Best Cutoff \\
\hline Sitting time/d & 0.58 & 61 & 62 & 1.69 & $\geq 5 \mathrm{~h} 20 \mathrm{~min}$ \\
\hline Lying time/d & 0.57 & 66 & 52 & 1.36 & $\geq 1 \mathrm{~h} 20 \mathrm{~min}$ \\
\hline Lying + sitting time/d & 0.63 & 54 & 72 & 1.89 & $\geq 8$ \\
\hline $\mathrm{ST} / \mathrm{d}<1.5 \mathrm{MET}$ & 0.76 & 84 & 65 & 2.39 & $\geq 8.5 \mathrm{~h}$ \\
\hline $\mathrm{ST} / \mathrm{d}<2 \mathrm{MET}$ & 0.69 & 74 & 61 & 1.88 & $\geq 9 \mathrm{~h}$ \\
\hline Average of MET/d & 0.67 & 64 & 73 & 2.40 & $\leq 1.5 \mathrm{MET}$ \\
\hline \multicolumn{6}{|c|}{$\begin{array}{l}\text { Prediction of mortality was during a median (interquartile range) of } 62 \text { (43-88) months of follow-up. } \\
\text { AUC }=\text { area under the curve; receiver operating characteristic curve analysis } \\
\text { ST/d }<1.5 \mathrm{MET}=\text { time spent/d in sedentary activities requiring }<1.5 \text { metabolic equivalents of task } \\
\text { ST/d }<2 \mathrm{MET}=\text { time spent/d in sedentary activities requiring }<2 \text { metabolic equivalents of task } \\
\text { MET }=\text { metabolic equivalent of task }\end{array}$} \\
\hline
\end{tabular}

ificity, which means that only time/d $<1.5$ MET presented acceptable discrimination.

Figure 1 shows the Kaplan-Meier curves with each logrank test comparison. The negative impact of sedentarism was presented in 5 of the survival curves according to the identified cutoff points. Time to death (or time of survival) was shorter in more sedentary subjects $(\geq 5 \mathrm{~h} 20 \mathrm{~min}$ of sitting time/d; $\geq 8 \mathrm{~h}$ of lying + sitting time/d; $\geq 8.5 \mathrm{~h}$ of time/d $<1.5 \mathrm{MET} ; \geq 9 \mathrm{~h}$ of time/d $<2 \mathrm{MET}$; and average of MET $\leq 1.5 \mathrm{MET} / \mathrm{d}(P<.05$ for all $)$.

The Cox regression models according to the proposed cutoff values showed that significant hazard ratios in the univariate survival analysis (Table 3) were observed for the same 5 variables with shorter time to death (Fig. 1) $(P<.05$ for all). After adjusting for all relevant confounders, only 2 threshold values of sedentarism variables were significant (Table 2). The strongest independent cutoff for predicting mortality was $\geq 8.5 \mathrm{~h} / \mathrm{d}$ spent in sedentary activities $<1.5$ MET. Furthermore, univariate analysis showed that each $\mathrm{h} / \mathrm{d}$ spent $<1.5 \mathrm{MET}$ increases mortality risk by $42 \%$ (hazard ratio 1.42 , 95\% CI 1.15-1.76, $P=.001$ ); however, this analysis was not significant in the adjusted model.

\section{Discussion}

The present study was the first to propose a cutoff point of objectively measured time spent in sedentary behavior in subjects with COPD and to investigate its association with mortality. It was found that mortality risk in subjects with COPD was 4.09 times higher in those subjects who spent $\geq 8.5 \mathrm{~h} / \mathrm{d}$ in activities requiring $<1.5 \mathrm{MET}$. It should be highlighted that there are available cutoff values to identify sedentary behavior in the general population that are based on subjective variables, such as self-reported time spent watching television. ${ }^{5,27}$ However, objective measures allow for more robust assessments of sedentarism variables in comparison with self-reported methods. ${ }^{7,10}$
Waschki et $\mathrm{al}^{2}$ found that objectively measured physical activity is the strongest predictor of all-cause mortality in subjects with COPD using the physical activity level of $>1.70$ to define an active person, between 1.40 and 1.69 to define a sedentary person, and $<1.40$ to define a very inactive person. Additionally, Garcia-Rio et $\mathrm{al}^{3}$ classified subjects with COPD according to the quartiles of vector magnitude units (ie, quartile 1: $<130$ vector magnitude units; quartile 2: 130-200 vector magnitude units; quartile 3: $200-270$ vector magnitude units; quartile $4>270$ vector magnitude units) and concluded that daily physical activity reduction was also associated with a higher mortality risk. Although these studies present undisputed relevance, conceptualizing sedentary behavior as distinct from lack of physical activity is important to avoid confusion and differentiate deleterious effects from subjects physically inactive from those with a sedentary lifestyle. In fact, individuals can achieve high levels of moderate-to-vigorous physical activity and still present high levels of sedentary behavior. ${ }^{5}$

A recent study ${ }^{35}$ examined the association between selfreported average time of television viewing duration/d and COPD-related mortality. After a follow-up of $19 \mathrm{y}$, the study found that men who watched television for $>4 \mathrm{~h} / \mathrm{d}$ were more likely to die of COPD than those who watched television for $<2 \mathrm{~h} / \mathrm{d}$ (hazard ratio $1.63,95 \%$ CI 1.04 2.55). ${ }^{35}$ By providing objective measurement instead of self-reported methods, the present study confirmed that time to death is shorter in those subjects who spent more time in sedentary postures (ie, sitting or lying + sitting) despite the poor discriminative power of these cutoff points. Furthermore, also by using an objective assessment, Hartman et al ${ }^{17}$ showed that longer sitting time in daily life is associated with a higher number of COPD exacerbations. The adjusted predictive value of sitting time/d for mortality in the present study was not significant as it was for time/d $<1.5$ MET or $<2$ MET. This indicates that activity intensity is also a key point for higher risk of death in 

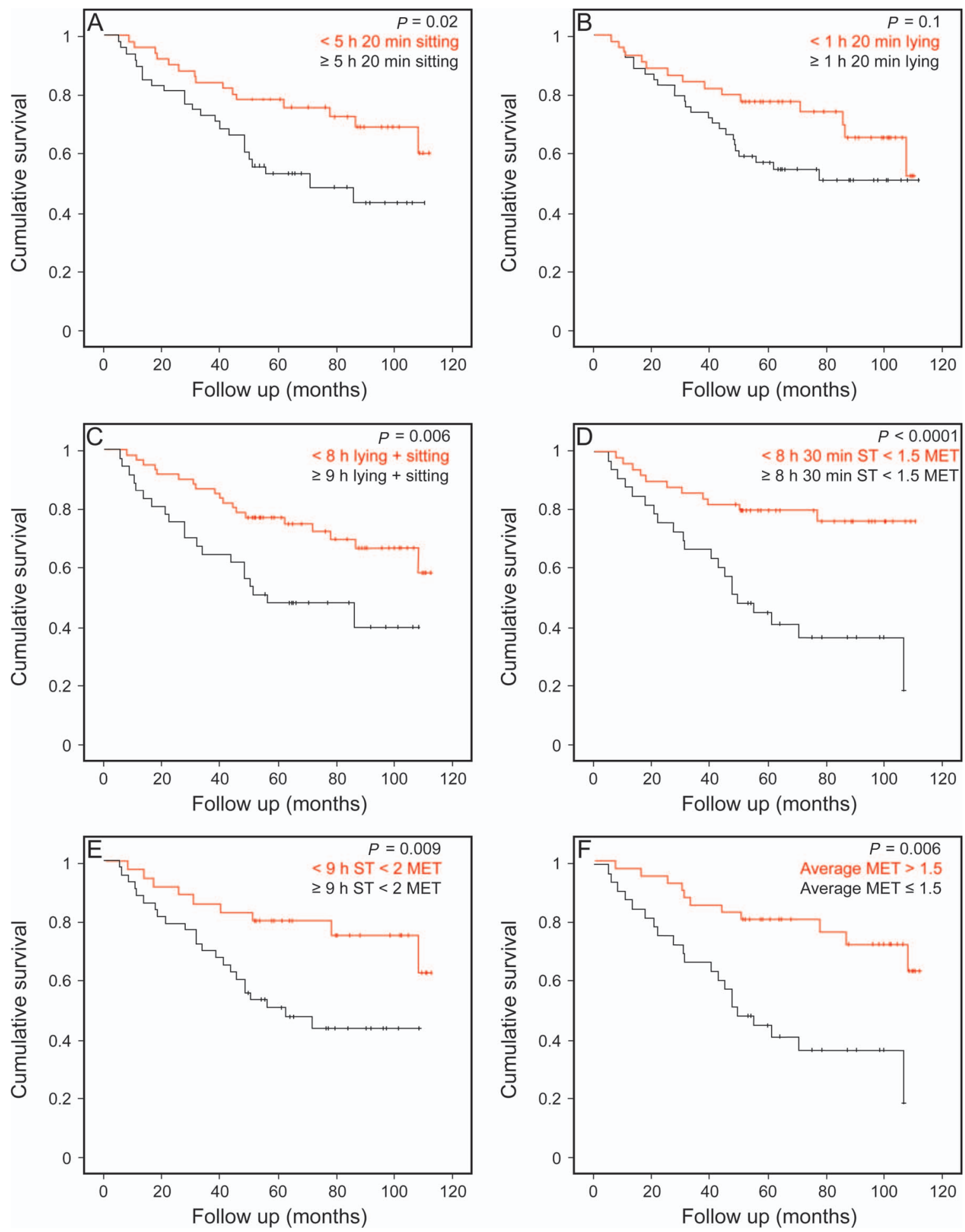

Fig. 1. Kaplan-Meier figure of cumulative survival with the log-rank test of the variables separated according to the sedentarism cutoff points. A: $\geq 5$ h $20 \mathrm{~min} / \mathrm{d}$ of sitting time; B: $\geq 1 \mathrm{~h} 20 \mathrm{~min} / \mathrm{d}$ of lying time; C: $\geq 8 \mathrm{~h} / \mathrm{d}$ of lying + sitting time; D: $\geq 8.5 \mathrm{~h} / \mathrm{day}$ of time spent in sedentary activities <1.5 MET; E: $\geq 9 \mathrm{~h} / \mathrm{d}$ of time spent in sedentary activities <2 MET; F: Average of MET <1.5 MET/d. Log-rank tests were performed to compare time to death. ST $<2 \mathrm{MET}=$ time spent/d in sedentary activities requiring $<2 \mathrm{MET}$. MET = metabolic equivalent of task. 
Table 3. Prognostic Values for Mortality of Six Sedentarism Cutoff Points by Cox Proportional Models

\begin{tabular}{|c|c|c|c|c|}
\hline Sedentarism Variables & Unadjusted HR (95\% CI) & $P$ & Adjusted HR (95\%CI) & $P$ \\
\hline Sitting time ( $\geq 5$ h $20 \mathrm{~min} / \mathrm{d}$ ) & $2.21(1.15-4.25)$ & .02 & $1.82(0.80-4.17)$ & .16 \\
\hline Lying time $/ \mathrm{d}(\geq 1$ h $20 \mathrm{~min} / \mathrm{d})$ & $1.72(0.89-3.32)$ & .10 & $1.48(0.62-3.53)$ & .38 \\
\hline Lying + sitting time $/ \mathrm{d}(\geq 8 \mathrm{~h} / \mathrm{d})$ & $2.37(1.26-4.47)$ & .008 & $1.92(0.86-4.28)$ & .11 \\
\hline $\mathrm{ST} / \mathrm{d}<1.5 \mathrm{MET}(\geq 8.5 \mathrm{~h} / \mathrm{d})$ & $3.66(1.76-7.61)$ & .001 & $4.09(1.90-8.78)$ & $<.001$ \\
\hline $\mathrm{ST} / \mathrm{d}<2 \mathrm{MET}(\geq 9 \mathrm{~h} / \mathrm{d})$ & $2.74(1.25-6.01)$ & .01 & $3.11(1.38-7.01)$ & .006 \\
\hline Average of MET ( $\leq 1.5 \mathrm{MET} / \mathrm{d})$ & $2.61(1.28-5.31)$ & .008 & $1.74(0.53-5.68)$ & .36 \\
\hline
\end{tabular}

Univariate analysis (unadjusted) and multivariate analyses (adjusted) were used. Cox regressions were adjusted for sex, age, body mass index, educational level, lung function, functional exercise capacity, and moderate-to-vigorous physical activity.

$\mathrm{HR}=$ hazard ratio

$\mathrm{ST} / \mathrm{d}<1.5 \mathrm{MET}=$ time spent/d in sedentary activities requiring $<1.5$ metabolic equivalents of task

$\mathrm{ST} / \mathrm{d}<2 \mathrm{MET}=$ time spent/d in sedentary activities requiring $<2$ metabolic equivalents of task

MET $=$ metabolic equivalent of task

COPD. The present results point out that the combination of time (duration) of sedentarism and very low intensity of activities (as in time/d $<1.5 \mathrm{MET}$ or $<2 \mathrm{MET}$ ) may be a more relevant outcome as a prognostic factor than only time spent sitting/d. This is in line with the study by DonaireGonzalez et al, ${ }^{36}$ which recently suggested that benefits of physical activity on COPD hospitalization also depend on intensity. Future studies with larger samples may provide a more in-depth investigation of the role of sitting time/d by itself as a prognostic factor for mortality in subjects with COPD, as observed in the general population. $5,6,8,27$

Despite the low area under the curve value, the cutoff point of average MET/d with the best sensitivity and specificity values for mortality in the present study was 1.5 $\mathrm{MET} / \mathrm{d}$, exactly the same threshold of intensity present in the definition of the term sedentarism. ${ }^{11}$ The threshold of 2 MET as the lower limit for light activity has been used previously in subjects with COPD, ${ }^{37}$ since 2 MET is the minimum intensity associated with activities performed in the upright posture, such as folding clothes or preparing a meal. ${ }^{26}$ Moreover, a study examining the use of the 1.5 MET threshold in the definition of sedentary behavior in adults against indirect calorimetry concluded that some common sitting behaviors appeared to have an MET level above this threshold. ${ }^{38}$ These findings have specific relevance to the current definition of sedentary behavior and suggest that common sitting activities, such as typing (eg, working in a computer), are actually defined as non-sedentary in a large proportion of the population. ${ }^{38}$ Although it has been shown that there is influence of the use of different activity thresholds in subjects with COPD, ${ }^{22}$ this issue was not yet investigated in depth.

A previous study has shown that sedentary time of subjects with COPD was significantly and positively associated with metabolic risk factors, such as waist circumference and glucose levels. ${ }^{39}$ Surprisingly, we could not find any study investigating the prognostic value of mortality using 1.5 MET intensity as a threshold for sedentarism.
This might have happened because the focus of the studies has instead been on physical activity/inactivity and not on sedentarism. Future research may focus on confirming this for different stages of disease severity.

In the present study, lying time had no influence on mortality when analyzed solely (Table 3 ). This was not surprising, since there was no difference in lying time/d between survivors and non-survivors (Table 1). A recent review about the use of time in daily life by subjects with COPD $^{14}$ found a median of time spent lying of $88 \mathrm{~min} / \mathrm{d}$, therefore very close to our cutoff point of $80 \mathrm{~min} / \mathrm{d}$. Perhaps a discriminative cutoff point for lying time was not detected in the present sample. Additionally, it might be that this variable is not capable of discriminating its influence on mortality when analyzed separately, and this hypothesis is reinforced by its low specificity value (ie, 52\%; Table 2), the lowest among the 6 studied variables.

Despite this study presenting some strengths, such as the clinical relevance and the addition of novel information to the literature, it also shows some limitations, such as the lack of assessment of bouts of sedentary time. Various studies in the general population have emphasized the importance of interrupting continuous periods of sedentary time, $, 8,27,40$ and this analysis would certainly also be interesting for subjects with COPD. Further, the best cutoff point suggested of $8.5 \mathrm{~h} / \mathrm{d}$ spent $<1.5 \mathrm{MET}$ matches with approximately $70 \%$ of wearing time; therefore, the applicability of the proposed cutoff points of sedentarism and each respective proportion of wearing time must be tested in other populations with different wearing times of the activity monitors. Moreover, perhaps the relatively small sample size of the study underpowered the comparison analysis of comorbidities between survivors and non-survivors. Unfortunately, it was not possible to identify whether more severe (ie, life-threatening) comorbidities were more prevalent among non-survivors in this sample. Future prospective studies with larger samples are encouraged to investigate sedentary behavior in depth as well as 


\section{Sedentary Behavior and Mortality in COPD}

to better investigate its association with comorbities, since comorbidities commonly impact physical activity variables in COPD. ${ }^{41}$

\section{Conclusion}

Sedentary behavior is an independent predictor of mortality in subjects with COPD, even adjusting for moderateto-vigorous physical activity and a number of other variables. Cutoff points from variables that combine duration of sedentary time and intensity $<1.5$ MET or $<2$ MET were associated with increased risk of mortality. Sedentary patients with increased risk of mortality can be identified by spending $\geq 8.5 \mathrm{~h} / \mathrm{d}$ (or equivalent to $\geq 70 \%$ of the objective monitoring wearing time, in the case of this study) in sedentary activities requiring $<1.5$ MET. These findings may open room for future studies aiming at decreasing sedentary time as a promising strategy to reduce mortality risk in patients with COPD.

\section{ACKNOWLEDGMENTS}

We are grateful to the colleagues from the Laboratory of Research in Respiratory Physiotherapy and to the employees and management from the Center of Information on Mortality and the Health Secretary of Londrina for contributing to data collection.

\section{REFERENCES}

1. Gimeno-Santos E, Frei A, Steurer-Stey C, de Batlle J, Rabinovich RA, Raste Y, et al. Determinants and outcomes of physical activity in patients with COPD: a systematic review. Thorax 2014;69(8):731739 .

2. Waschki B, Kirsten A, Holz O, Müller KC, Meyer T, Watz H, et al. Physical activity is the strongest predictor of all-cause mortality in patients with COPD: a prospective cohort study. Chest 2011;140(2): 331-342.

3. Garcia-Rio F, Rojo B, Casitas R, Lores V, Madero R, Romero D, et al. Prognostic value of the objective measurement of daily physical activity in patients with COPD. Chest 2012;142(2):338-346.

4. Vaes AW, Garcia-Aymerich J, Marott JL, Benet M, Groenen MT, Schnohr P, et al. Changes in physical activity and all-cause mortality in COPD. Eur Respir J 2014;44(5):1199-1209.

5. Tremblay MS, Colley RC, Saunders TJ, Healy GN, Owen N. Physiological and health implications of a sedentary lifestyle. Appl Physiol Nutr Metab 2010;35(6):725-740.

6. Katzmarzyk PT, Church TS, Craig CL, Bouchard C. Sitting time and mortality from all causes, cardiovascular disease, and cancer. Med Sci Sports Exerc 2009;41(5):998-1005.

7. Hill K, Gardiner PA, Cavalheri V, Jenkins SC, Healy GN. Physical activity and sedentary behaviour: applying lessons to chronic obstructive pulmonary disease. Intern Med J 2015;45(5):474-482.

8. Owen N, Healy GN, Matthews CE, Dunstan DW. Too much sitting: the population health science of sedentary behavior. Exerc Sport Sci Rev 2010;38(3):105-113.

9. Sedentary Behaviour Research Network. Letter to the editor: standardized use of the terms "sedentary" and "sedentary behaviours". Appl Physiol Nutr Metab 2012;37(3):540-542.

10. Cavalheri V, Straker L, Gucciardi DF, Gardiner PA, Hill K. Changing physical activity and sedentary behaviour in people with COPD. Respirology 2016;21(3):419-426.
11. Gibbs BB, Hergenroeder AL, Katzmarzyk PT, Lee IM, Jakicic JM. Definition, measurement, and health risks associated with sedentary behavior. Med Sci Sports Exerc 2015;47(6):1295-1300.

12. Garber CE, Blissmer B, Deschenes MR, Franklin BA, Lamonte MJ, Lee IM, et al. American College of Sports Medicine position stand: quantity and quality of exercise for developing and maintaining cardiorespiratory, musculoskeletal, and neuromotor fitness in apparently healthy adults: guidance for prescribing exercise. Med Sci Sports Exerc 2011;43(7):1334-1359.

13. Pitta F, Troosters T, Spruit MA, Probst VS, Decramer M, Gosselink R. Characteristics of physical activities in daily life in chronic obstructive pulmonary disease. Am J Respir Crit Care Med 2005;171(9): 972-977.

14. Hunt T, Madigan S, Williams MT, Olds TS. Use of time in people with chronic obstructive pulmonary disease: a systematic review. Int J Chron Obstruct Pulmon Dis 2014;9:1377-1388

15. Andrianopoulos V, Wouters EF, Pinto-Plata VM, Vanfleteren LE, Bakke PS, Franssen FM, et al. Prognostic value of variables derived from the six-minute walk test in patients with COPD: results from the ECLIPSE study. Respir Med 2015;109(9):1138-1146.

16. Watz H, Pitta F, Rochester CL, Garcia-Aymerich J, ZuWallack R, Troosters T, et al. An official European Respiratory Society statement on physical activity in COPD. Eur Respir J 2014;44(6):15211537.

17. Hartman JE, Boezen HM, de Greef MH, Ten Hacken NH. Physical and psychosocial factors associated with physical activity in patients with chronic obstructive pulmonary disease. Arch Phys Med Rehabil 2013;94(12):2396-2402.e7

18. Biswas A, Oh PI, Faulkner GE, Bajaj RR, Silver MA, Mitchell MS, Alter DA. Sedentary time and its association with risk for disease incidence, mortality, and hospitalization in adults: a systematic review and meta-analysis. Ann Intern Med 2015;162(2):123-132.

19. Probst VS, Kovelis D, Hernandes NA, Camillo CA, Cavalheri V, Pitta F. Effects of 2 exercise training programs on physical activity in daily life in patients with COPD. Respir Care 2011;56(11):17991807.

20. Global Strategy for the Diagnosis, Management, and Prevention of Chronic Obstructive Pulmonary Disease. Updated 2016. Available from: www.goldcopd.org. Accessed February 10, 2016.

21. Cindy Ng LW, Mackney J, Jenkins S, Hill K. Does exercise training change physical activity in people with COPD? A systematic review and meta-analysis. Chron Respir Dis 2012;9(1):17-26.

22. Demeyer H, Burtin C, Van Remoortel H, Hornikx M, Langer D, Decramer M, et al. Standardizing the analysis of physical activity in patients with COPD following a pulmonary rehabilitation program. Chest 2014;146(2):318-327.

23. Rabinovich RA, Louvaris Z, Raste Y, Langer D, Van Remoortel H, Giavedoni S, et al. Validity of physical activity monitors during daily life in patients with COPD. Eur Respir J 2013;42(5):1205-1215.

24. Cavalheri V, Donária L, Ferreira T, Finatti M, Camillo CA, Cipulo Ramos EM, Pitta F. Energy expenditure during daily activities as measured by two motion sensors in patients with COPD. Respir Med 2011;105(6):922-929.

25. Hill K, Dolmage TE, Woon L, Goldstein R, Brooks D. Measurement properties of the SenseWear armband in adults with chronic obstructive pulmonary disease. Thorax 2010;65(6):486-491.

26. Ainsworth BE, Haskell WL, Herrmann SD, Meckes N, Bassett DR, Jr., Tudor-Locke C, et al. 2011 compendium of physical activities: a second update of codes and MET values. Med Sci Sports Exerc 2011;43(8):1575-1581.

27. Ford ES, Caspersen CJ. Sedentary behaviour and cardiovascular disease: a review of prospective studies. Int J Epidemiol 2012;41(5): 1338-1353. 


\section{Sedentary Behavior and Mortality in COPD}

28. Miller MR, Hankinson J, Brusasco V, Burgos F, Casaburi R, Coates A, et al. Standardisation of spirometry. Eur Respir J 2005;26(2):319-338.

29. Pereira CA, Sato T, Rodrigues SC. New reference values for forced spirometry in white adults in Brazil. J Bras Pneumol 2007;33(4): 397-406.

30. ATS Committee on Proficiency Standards for Clinical Pulmonary Function Laboratories. ATS statement: guidelines for the six-minute walk test. Am J Respir Crit Care Med 2002;166(1):111-117.

31. Britto RR, Probst VS, de Andrade AF, Samora GA, Hernandes NA, Marinho PE, et al. Reference equations for the six-minute walk distance based on a Brazilian multicenter study. Braz J Phys Ther 2013;17(6):556-563.

32. Kovelis D, Segretti NO, Probst VS, Lareau SC, Brunetto AF, Pitta F. Validation of the modified pulmonary functional status and dyspnea questionnaire and the Medical Research Council scale for use in Brazilian patients with chronic obstructive pulmonary disease. J Bras Pneumol 2008;34(12):1008-1018.

33. Bestall JC, Paul EA, Garrod R, Garnham R, Jones PW, Wedzicha JA. Usefulness of the Medical Research Council (MRC) dyspnoea scale as a measure of disability in patients with chronic obstructive pulmonary disease. Thorax 1999;54(7):581-586.

34. Garcia-Aymerich J, Lange P, Benet M, Schnohr P, Antó JM. Regular physical activity modifies smoking-related lung function decline and reduces risk of chronic obstructive pulmonary disease: a populationbased cohort study. Am J Respir Crit Care Med 2007;175(5):458463.
35. Ukawa S, Tamakoshi A, Yatsuya H, Yamagishi K, Ando M, Iso H. Association between average daily television viewing time and chronic obstructive pulmonary disease-related mortality: findings from the Japan Collaborative Cohort Study. J Epidemiol 2015;25(6): 431-436.

36. Donaire-Gonzalez D, Gimeno-Santos E, Balcells E, de Batlle J, Ramon MA, Rodriguez E, et al. Benefits of physical activity on COPD hospitalisation depend on intensity. Eur Respir J 2015;46(5):12811289.

37. Hill K, Dolmage TE, Woon L, Coutts D, Goldstein R, Brooks D. Defining the relationship between average daily energy expenditure and field-based walking tests and aerobic reserve in COPD. Chest 2012;141(2):406-412.

38. Mansoubi M, Pearson N, Clemes SA, Biddle SJ, Bodicoat DH, Tolfrey $\mathrm{K}$, et al. Energy expenditure during common sitting and standing tasks: examining the 1.5 MET definition of sedentary behaviour. BMC Public Health 2015;15:516.

39. Park SK, Larson JL. The relationship between physical activity and metabolic syndrome in people with chronic obstructive pulmonary disease. J Cardiovasc Nurs 2014;29(6):499-507.

40. Owen N. Sedentary behavior: understanding and influencing adults' prolonged sitting time. Prev Med 2012;55(6):535-539.

41. Sievi NA, Senn O, Brack T, Brutsche MH, Frey M, Irani S, et al. Impact of comorbidities on physical activity in COPD. Respirology 2015;20(3):413-418. 